\title{
Doses e Épocas de Aplicação de Redutor de Crescimento afetando Cultivares de Trigo em Duas Doses de Nitrogênio ${ }^{1}$
}

\author{
Rates and Application Times of Growth Reducer Affecting Wheat Cultivars at Two Nitrogen \\ Rates
}

ZAGONEL, J. ${ }^{2}$ e FERNANDES, E.C. ${ }^{3}$

\begin{abstract}
RESUMO - Os redutores de crescimento têm sido utilizados com sucesso em trigo, evitando o acamamento, mas a recomendação de uso não diferencia cultivares quanto ao porte. Visando determinar a dose e a época de aplicação mais adequadas de trinexapac-ethyl (Moddus), em cultivares de trigo, realizaram-se experimentos na Fazenda Escola da Universidade Estadual de Ponta Grossa, no ano de 2005. O delineamento experimental foi de blocos ao acaso, em esquema fatorial $2 \times 2 \times 6$, com três repetições para cada cultivar de trigo. Os tratamentos constaram de duas doses de nitrogênio (50 e $240 \mathrm{~kg} \mathrm{ha}^{-1}$ ), duas épocas de aplicação de trinexapac-ethyl (entre o $1^{\circ}$ e o $2^{\circ}$ nó e entre o $2^{\circ}$ e o $3^{\circ}$ nó perceptível) e de seis doses de trinexapac-ethyl $\left(0,31,2,62,5,93,7,125,0\right.$ e 156,2 $\left.\mathrm{g} \mathrm{ha}^{-1}\right)$. Foram utilizados oito cultivares de trigo com diferentes respostas ao acamamento: OR-1, CD-104 e CD-105 (resistentes), Alcover, Ônix e Vanguarda (moderadamente resistentes), Supera (moderadamente suscetivel) e CEP-24 (suscetivel). Avaliaram-se características agronômicas, componentes da produção e produtividade. O clima ameno não foi favorável à ocorrência de acamamento, que foi observado somente para as menores doses de trinexapac-ethyl no cultivar CEP-24. A dose de nitrogênio afetou características da planta e a produtividade de alguns cultivares. O estádio de aplicação de trinexapac-ethyl não afetou de forma substancial a produtividade, e sim a altura das plantas, que foi menor quanto mais tardia a aplicação. Em geral, a equação de ajuste da produtividade em relação às doses de trinexapacethyl foi quadrática, ocorrendo aumento da produção com o aumento da dose do redutor, até um limite, variável de acordo com o cultivar.
\end{abstract}

Palavras-chave: altura de planta, acamamento de planta, produtividade, trinexapac-ethyl, Triticum aestivum .

ABSTRACT - Growth reducers have been used successfully in wheat, preventing lodging, but use recommendation does not differentiate cultivar height. Experiments were conducted at the UEPG School Farm in 2005 to determine the rate and time of trinexapac-ethyl (Moddus) application in wheat cultivar. The experimental was arranged in complete randomized blocks, in a $2 \times 2 \times 6$ factorial scheme, with three repetitions for each wheat cultivar. The treatments consisted of two nitrogen rates (50 and $240 \mathrm{~kg} \mathrm{ha}{ }^{-1}$ ), two trinexapac-ethyl application times (between first and second knot and between second and third perceivable knot) and six trinexapac-ethyl rates $(0$, 31.2, 62.5, 93.7, 125.0 and $\left.156.2 \mathrm{~g} \mathrm{ha}^{-1}\right)$. Eight wheat cultivars of different lodging performances were used: OR-1, CD-104 and CD-105 (resistant), Alcover, Onix and Vanguarda (moderately resistant), Supera (moderately susceptible), and CEP-24 (susceptible).Agronomical characteristics, yield components and yield were evaluated. Mild climate was not favorable to lodging occurrence, only observed for the lesser trinexapac-ethyl rates in CEP-24 cultivar. Nitrogen rate affected plant characteristics and the yield of some cultivars. The trinexapac-ethyl application stage did not substantially affect yield, but rather plant height, which became smaller the more delayed the application was. In general, yield adjustment equation in relation to the trinexapac-ethyl rates was quadratic, with yield increasing with increasing reducer rate, up to a limit, varying according to the cultivar.

Keywords: plant height, lodging, yield, trinexapac-ethyl, Triticum aestivum.

Recebido para publicação em 24.8.2006 e na forma revisada em 17.4.2007.

Professor, Doutor, Dep. de Fitotecnia e Fitossanidade da Universidade Estadual de Ponta Grossa- UEPG, Av. Carlos Cavalcanti, 4748, 84030-900 Ponta Grossa-PR, <jefersonzagonel@uol.com.br>; ${ }^{3}$ Acadêmica do curso de Agronomia - UEPG, <elianacfernandes@uol.com.br>. 


\section{INTRODUÇÃO}

O lançamento de cultivares modernos de trigo, com alto potencial de produtividade, está ligado também a um maior uso de insumos, entre os quais a adubação nitrogenada. No entanto, o uso de altas doses de nitrogênio pode resultar em acamamento de plantas de trigo um fenômeno que compromete a produtividade e qualidade dos grãos. Quando ocorre na fase de enchimento de grãos, compromete a produtividade, por limitar a fotossíntese e a translocação de fotoassimilados. Na maturação, as plantas acamadas deixam as espigas mais próximas do solo, em ambiente mais úmido, o que acarreta diminuição do peso hectolitrico, germinação ou apodrecimento do grão, além de dificultar a colheita mecanizada.

A quantidade do nitrogênio a ser aplicada deve-se basear em alguns fatores. Em solos com alta quantidade de matéria orgânica as doses podem ser menores (Mundstock, 1983). No trigo cultivado após soja, a quantidade de nitrogênio aplicado pode ser menor do que a utilizada após gramíneas (Iapar, 2000). Os cultivares de maior estatura estão sujeitos ao acamamento, portanto as doses devem ser mais baixas (Silva \& Goto, 1990). Em geral, são usadas doses de 30 a $60 \mathrm{~kg} \mathrm{ha}^{-1}$ de nitrogênio, mas alguns cultivares podem responder até $120 \mathrm{~kg} \mathrm{ha}^{-1}$, se o clima e o solo forem favoráveis (Freitas et al., 1994). Embora existam variações nas respostas às doses de nitrogênio de acordo com o cultivar, clima, solo e outros, a maioria dos resultados mostra que o uso desse nutriente, mesmo em doses baixas, resulta sempre em produtividades superiores em relação à ausência de uso do nutriente (Vieira et al., 1995).

Entre as estratégias para o uso de altas doses de nitrogênio, sem a ocorrência de acamamento está o uso de cultivares de porte baixo e/ou de redutores de crescimento. O trinexapacethyl é um redutor de crescimento utilizado em cereais de inverno que promove redução acentuada do comprimento do caule (Fagerness \& Penner, 1998) e, cons eqüentemente, da altura da planta, evitando o acamamento (Amrein et al., 1989). O trinexapac-ethyl atua nas plantas, reduzindo a elongação celular no estádio vegetativo e obstruindo a biossíntese do ácido giberélico (Heckman et al., 2002).
O trinexapac-ethyl reduz drasticamente o nível do ácido giberélico ativo $\left(\mathrm{GA}_{1}\right)$, por inibir a enzima 3 $\beta$-hidroxilase (Nakayama et al., 1990), e, assim, aumenta acentuadamente seu precursor biossintético imediato, o $\mathrm{GA}_{20}$ (Davies, 1987). A queda no nivel do ácido giberélico ativo $\left(\mathrm{GA}_{1}\right)$ é a provável causa da redução do crescimento das plantas (Weiler \& Adams, 1991).

No Brasil, o produto foi avaliado por Zagonel et al. (2002a) no cultivar OR-1, de porte baixo, que verificaram redução do comprimento dos entrenós e aumento do número de espigas por metro e da produtividade. Em outro experimento, no mesmo ano e local (Ponta Grossa, PR), Zagonel et al. (2002 b) trabalharam com o cultivar IAPAR-53, de porte médio/alto, e também constataram redução substancial da estatura das plantas pelo encurtamento dos entrenós, com aumento de produtividade. Nos dois cultivares não foi observado acamamento, porém foram nítidas as vantagens da aplicação do produto nas características avaliadas.

A dose recomendada de trinexapac-ethyl em trigo é de 100 a $125 \mathrm{~g} \mathrm{ha}^{-1}$, aplicada entre o primeiro e o segundo nó perceptivel. Essa recomendação é ampla e não distingue o cultivar, embora possam responder de maneira diferencial em relação à dose do produto. Zagonel (2003), em trabalho com doses de trinexapac-ethyl e dois cultivares, verificou que com o aumento da dose do redutor a altura de plantas diminuiu linearmente em ambos os cultivares, mas somente em uma houve vantagem na redução do acamamento. A produtividade não foi afetada, mostrando que a dose a ser utilizada nos cultivares pode ser diferente.

O objetivo deste trabalho foi avaliar os efeitos do redutor de crescimento trinexapacethyl - em diferentes doses e épocas de aplicação - em características agronômicas, componentes da produção e na produtividade de cultivares de trigo em duas doses de nitrogênio.

\section{MATERIAL E MÉTODOS}

Os experimentos foram instalados no ano de 2005, na Fazenda Escola da Universidade Estadual de Ponta Grossa, no município de Ponta Grossa-PR. Utilizou-se o sistema de "plantio direto na palha", com semeadura do 
trigo realizada no dia 27.6.2005. A adubação de base consistiu da aplicação de $300 \mathrm{~kg} \mathrm{ha}^{-1}$ de adubo 08-30-20 na semeadura. As parcelas foram compostas de 14 fileiras de trigo de 5,0 m de comprimento, espaçadas de 0,17 m. Considerou-se como área útil as dez fileiras centrais das parcelas, desprezando-se 0,50 m em cada extremidade. O solo no local é um Cambissolo distrófico de textura argilosa. A análise química do solo, para amostragem de 0 a $10 \mathrm{~cm}$, revelou os seguintes resultados: $\mathrm{pH}\left(\mathrm{CaCl}_{2}\right)=4,9 ; \mathrm{Ca}^{++}=4,2 \mathrm{cmol}_{\mathrm{c}} \mathrm{dm}^{-3} ; \mathrm{Ca}+$ $\mathrm{Mg}=6,9 \mathrm{cmol}_{\mathrm{c}} \mathrm{dm}^{-3} ; \mathrm{K}=0,63 \mathrm{cmol}_{\mathrm{c}} \mathrm{dm}^{-3}$; $\mathrm{P}=12,6 \mathrm{mg} \mathrm{dm}^{-3} ; \mathrm{C}=32 \mathrm{~g} \mathrm{dm}^{-3} ; \mathrm{H}+\mathrm{Al}=$ $7,2 \mathrm{cmol}_{\mathrm{c}} \mathrm{dm}^{-3} ; \mathrm{Al}^{+++}=0,2 ; \mathrm{CTC}=14,7 ; \mathrm{e} \mathrm{V \%}=$ 51. A análise granulométrica mostrou, em $\mathrm{g} \mathrm{kg}^{-1}$ : argila - 460; silte - 179; e areia - 361 .

Foram realizados oito experimentos, um para cada cultivar de trigo de diferente resposta ao acamamento: OR-1, CD-104 e CD-105 (resistentes), Alcover, Ônix e Vanguarda (moderadamente resistentes), Supera (moderadamente suscetivel) e CEP-24 (suscetivel).

Para todos os experimentos, o delineamento experimental utilizado foi de blocos ao acaso, com 24 tratamentos dispostos em esquema fatorial $2 \times 2 \times 6$, com três repetições. Os tratamentos constaram das combinações dos fatores doses de nitrogênio (50 e $\left.240 \mathrm{~kg} \mathrm{ha}^{-1}\right)$, na forma de uréia, aplicadas em cobertura no início do perfilhamento; épocas de aplicação de trinexapac-ethyl (entre o 1 ㅇ e o $2^{\circ}$ nó e entre o 2ㅇ e o 3ㅇ nó perceptível); e doses de trinexapac-ethyl $(0,31,2,62,5,93,7,125,0 \mathrm{e}$ 156,2 $\mathrm{g} \mathrm{ha}^{-1}$ ), correspondente a $0,125,250$, 375,500 e $625 \mathrm{~mL} \mathrm{ha}^{-1}$ de Moddus, respectivamente.

O trinexapac-ethyl foi aplicado com pulverizador costal, à pressão constante de $30 \mathrm{lb} \mathrm{pol}^{-2}$, pelo $\mathrm{CO}_{2}$ comprimido, com pontas de jato plano "leque" XR 110-02. Aplicou-se o equivalente a $200 \mathrm{~L} \mathrm{ha}^{-1}$ de calda.

Avaliaram-se características agronômicas no florescimento coletando dez plantas por parcela; a altura das plantas foi estimada medindo do nível do solo até a base da espiga; e o diâmetro do caule foi medido com paquímetro digital, na base da planta, a quatro centímetros do solo. Os componentes da produção foram determinados a partir da colheita das plantas de dois metros de fileira de cada parcela; o indice de colheita aparente foi determinado através da relação dos valores da massa da parte aérea da planta pelo peso de grãos. A produtividade foi determinada pela produção da área útil de cada parcela, corrigindo a umidade para $13 \%$. Os dados foram submetidos à análise da variância, e as diferenças entre as médias de doses de nitrogênio e de épocas de aplicação de trinexapac-ethyl foram comparadas pelo teste da DMS a 5\% de probabilidade e das doses de trinexapac-ethyl por regressão polinomial.

\section{RESULTADOS E DISCUSSÃO}

O clima ameno durante o experimento não foi favorável à ocorrência de acamamento, que só foi observado no cultivar CEP-24 nas menores doses e na ausência de trinexapac-ethyl. As características avaliadas (Tabelas 1 e 2) foram afetadas pela dose de nitrogênio e pela dose e época de aplicação do trinexapac-ethyl, com interação entre os fatores e resposta diferencial de acordo com o cultivar. A interação com as doses de nitrogênio, quando ocorreu, envolveu as doses e as épocas de aplicação de trinexapacethyl, mas somente para esses dois últimos fatores elas foram desdobradas.

A altura das plantas está ligada diretamente ao acamamento e pode ser afetada pela dose de nitrogênio, entre outros fatores. É, portanto, uma característica que deve ser modificada pelo uso de redutores de crescimento. Os cultivares CD-105 e CEP-24 foram os únicos que não tiveram a altura aumentada com o incremento da dose de nitrogênio (Tabela 1). Para a época de aplicação do trinexapac-ethyl, os cultivares responderam de forma diferenciada, não havendo diferença significativa para os cultivares CD-105, Alcover e Vanguarda e sendo observada menor altura para a aplicação mais tardia para os cultivares OR-1, CD-104 e CEP-24 (Tabela 1). Exceto para Ônix, os cultivares responderam de forma linear à dose de trinexapac-ethyl, diminuindo a altura com o aumento da dose do redutor (Figura 1). Essa resposta foi similar à observada em outros trabalhos (Zagonel, 2003; Zagonel et al., 2005; Zagonel \& Kunz, 2005), mostrando a efetividade do produto em reduzir a altura das plantas de trigo, independentemente do porte do cultivar. 
Tabela 1 - Características agronômicas, componentes da produção e produtividade das plantas de oito cultivares de trigo em função de doses de nitrogênio e de épocas de aplicação de trinexapac -ethyl. UEPG, Ponta Grossa-PR, 2005

\begin{tabular}{|c|c|c|c|c|c|c|c|c|}
\hline Dose/Época & OR-1 & CD-104 & CD-105 & Alcover & Ônix & Vanguar. & Supera & CEP-24 \\
\hline & \multicolumn{8}{|c|}{ Altura de plantas $(\mathrm{cm})$} \\
\hline Dose $\mathrm{N}-50^{1 /}$ & $67,0 \mathrm{~b}$ & $64,9 \mathrm{~b}$ & $71,4 \mathrm{a}$ & $67,9 \mathrm{~b}$ & $66,0 \mathrm{~b}$ & $67,7 \mathrm{~b}$ & $71,7 \mathrm{~b}$ & $98,1 \mathrm{a}$ \\
\hline Dose $N-240^{\underline{\underline{L}}}$ & $68,6 \mathrm{a}$ & $66,9 \mathrm{a}$ & $71,8 \mathrm{a}$ & $72,0 \mathrm{a}$ & $69,1 \mathrm{a}$ & $70,0 \mathrm{a}$ & $73,0 \mathrm{a}$ & $98,7 \mathrm{a}$ \\
\hline Época $1^{\circ}$ e $2^{\circ}$ nó & $68,7 \mathrm{a}$ & $66,5 \mathrm{a}$ & $71,7 \mathrm{a}$ & $70,2 \mathrm{a}$ & $64,7 \mathrm{~b}$ & $69,3 \mathrm{a}$ & $71,2 \mathrm{~b}$ & $99,5 \mathrm{a}$ \\
\hline Época $2^{2}$ e $3^{\circ}$ nó & $66,9 \mathrm{~b}$ & $65,3 \mathrm{~b}$ & $71,5 \mathrm{a}$ & $69,7 \mathrm{a}$ & $70,5 \mathrm{a}$ & $68,4 \mathrm{a}$ & $73,5 \mathrm{a}$ & $97,3 \mathrm{~b}$ \\
\hline \multirow[t]{2}{*}{ CV (\%) } & 2,9 & 3,3 & 3,3 & 3,8 & 3,4 & 3,9 & 3,4 & 3,5 \\
\hline & \multicolumn{8}{|c|}{ Diâmetro do caule (mm) } \\
\hline Dose $\mathrm{N}-50$ & $2,84 \mathrm{a}$ & $3,45 \mathrm{~b}$ & $2,97 \mathrm{a}$ & $3,0 \mathrm{a}$ & $3,03 \mathrm{a}$ & $2,81 \mathrm{a}$ & $3,00 \mathrm{a}$ & $3,11 \mathrm{a}$ \\
\hline Dose N -240 & $2,81 \mathrm{a}$ & $3,57 \mathrm{a}$ & $2,94 \mathrm{a}$ & $3,0 \mathrm{a}$ & $2,95 \mathrm{~b}$ & $2,79 \mathrm{a}$ & $3,00 \mathrm{a}$ & $3,12 \mathrm{a}$ \\
\hline Época $1^{\circ}$ e $2^{\circ}$ nó & $2,84 \mathrm{a}$ & $3,50 \mathrm{a}$ & $2,95 \mathrm{a}$ & $3,0 \mathrm{a}$ & $2,91 \mathrm{~b}$ & $2,79 \mathrm{a}$ & $2,97 \mathrm{a}$ & $3,13 \mathrm{a}$ \\
\hline Época $2^{\circ}$ e $3^{\circ}$ nó & $2,81 \mathrm{a}$ & $3,52 \mathrm{a}$ & $2,96 \mathrm{a}$ & $3,0 \mathrm{a}$ & $3,07 \mathrm{a}$ & $2,81 \mathrm{a}$ & $3,03 \mathrm{a}$ & $3,11 \mathrm{a}$ \\
\hline \multirow[t]{2}{*}{$\mathrm{CV}(\%)$} & 4,6 & 6,5 & 6,6 & 8,2 & 6,0 & 6,3 & 5,1 & 5,3 \\
\hline & \multicolumn{8}{|c|}{ Índice de colheita aparente } \\
\hline Dose $\mathrm{N}-50$ & $0,41 \mathrm{a}$ & $0,48 \mathrm{a}$ & $0,37 \mathrm{a}$ & $0,55 \mathrm{a}$ & $0,28 \mathrm{a}$ & $0,36 \mathrm{a}$ & 0,43 a & $0,37 \mathrm{a}$ \\
\hline Dose $\mathrm{N}-240$ & $0,39 \mathrm{a}$ & $0,43 \mathrm{~b}$ & $0,38 \mathrm{a}$ & $0,53 \mathrm{a}$ & $0,28 \mathrm{a}$ & $0,32 \mathrm{~b}$ & $0,44 \mathrm{a}$ & $0,32 \mathrm{~b}$ \\
\hline Época $1^{\circ}$ e $2^{\circ}$ nó & $0,42 \mathrm{a}$ & $0,46 \mathrm{a}$ & $0,40 \mathrm{a}$ & $0,56 \mathrm{a}$ & $0,31 \mathrm{a}$ & $0,34 \mathrm{a}$ & $0,44 \mathrm{a}$ & $0,34 \mathrm{a}$ \\
\hline Época $2^{ }$e $3^{\circ}$ nó & $0,39 \mathrm{a}$ & $0,45 \mathrm{a}$ & $0,36 \mathrm{~b}$ & $0,51 \mathrm{a}$ & $0,26 \mathrm{a}$ & $0,34 \mathrm{a}$ & $0,43 \mathrm{a}$ & $0,35 \mathrm{a}$ \\
\hline \multirow[t]{2}{*}{ CV (\%) } & 14,8 & 13,8 & 14,1 & 15,7 & 12,9 & 6,5 & 14,8 & 14,3 \\
\hline & \multicolumn{8}{|c|}{$\mathrm{N}^{\mathrm{o}}$ grãos $\mathrm{m}^{-2}$} \\
\hline Dose $\mathrm{N}-50^{\underline{\underline{Y}}}$ & $8.858 \mathrm{a}$ & $5.028 \mathrm{~b}$ & $6.333 \mathrm{a}$ & $6.871 \mathrm{a}$ & $8.783 \mathrm{~b}$ & $9.718 \mathrm{a}$ & $8.225 \mathrm{~b}$ & $5.646 \mathrm{~b}$ \\
\hline Dose N $-240^{\perp}$ & $9.225 \mathrm{a}$ & $6.765 \mathrm{a}$ & $6.098 \mathrm{a}$ & $6.513 \mathrm{a}$ & $10.022 \mathrm{a}$ & $9.000 \mathrm{~b}$ & $9.082 \mathrm{a}$ & $7.512 \mathrm{a}$ \\
\hline Época $1^{\circ}$ e $2^{\circ}$ nó & $8.893 \mathrm{a}$ & $6.022 \mathrm{a}$ & $6.613 a$ & $6.314 \mathrm{~b}$ & $8.907 \mathrm{~b}$ & $9.615 \mathrm{a}$ & $8.868 \mathrm{a}$ & $7.104 \mathrm{a}$ \\
\hline Época $2^{\circ}$ e $3^{\circ}$ nó & $9.190 \mathrm{a}$ & $5.771 \mathrm{a}$ & $5.818 \mathrm{~b}$ & $7.070 \mathrm{a}$ & $9.898 \mathrm{a}$ & $9.104 \mathrm{a}$ & $8.439 \mathrm{a}$ & $6.054 \mathrm{~b}$ \\
\hline \multirow[t]{2}{*}{ CV (\%) } & 12,1 & 17,8 & 21,4 & 19,0 & 13,2 & 13,4 & 18,2 & 20,8 \\
\hline & \multicolumn{8}{|c|}{ Peso de mil grãos (g) } \\
\hline Dose $\mathrm{N}-50$ & $27,2 \mathrm{a}$ & $26,0 \mathrm{a}$ & $25,6 \mathrm{a}$ & $28,5 \mathrm{a}$ & $20,2 \mathrm{~b}$ & $25,6 \mathrm{a}$ & $32,2 \mathrm{a}$ & $28,9 \mathrm{~b}$ \\
\hline Dose N-240 & $27,1 \mathrm{a}$ & $26,3 \mathrm{a}$ & $25,2 \mathrm{a}$ & $28,7 \mathrm{a}$ & $21,9 \mathrm{a}$ & $25,6 \mathrm{a}$ & $32,6 \mathrm{a}$ & $30,8 \mathrm{a}$ \\
\hline Época $1^{\circ}$ e $2^{\circ}$ nó & $26,5 \mathrm{~b}$ & $26,8 \mathrm{a}$ & $26,3 \mathrm{a}$ & $27,8 \mathrm{a}$ & $19,8 \mathrm{~b}$ & $25,8 \mathrm{a}$ & $32,0 \mathrm{a}$ & $31,0 \mathrm{a}$ \\
\hline Época $2^{\circ}$ e $3^{\circ}$ nó & $27,4 \mathrm{a}$ & $25,4 \mathrm{a}$ & $24,5 \mathrm{~b}$ & $29,4 \mathrm{a}$ & $22,3 \mathrm{a}$ & $25,3 \mathrm{a}$ & $32,8 \mathrm{a}$ & $28,7 \mathrm{~b}$ \\
\hline \multirow[t]{2}{*}{ CV (\%) } & 5,9 & 12,1 & 12,7 & 15,0 & 12,0 & 5,1 & 6,9 & 8,9 \\
\hline & \multicolumn{8}{|c|}{ Produtividade $\left(\mathrm{kg} \mathrm{ha}^{-1}\right)$} \\
\hline Dose N. 50 & $2.331 \mathrm{a}$ & $2.398 \mathrm{a}$ & $2.456 \mathrm{~b}$ & 3.783 a & $2.571 \mathrm{a}$ & $3.597 \mathrm{a}$ & $3.630 \mathrm{a}$ & $3.206 \mathrm{~b}$ \\
\hline Dose N -240 & $2.316 \mathrm{a}$ & $2.489 \mathrm{a}$ & $2.774 \mathrm{a}$ & $3.885 \mathrm{a}$ & $2.657 \mathrm{a}$ & $3.719 \mathrm{a}$ & $3.722 \mathrm{a}$ & $3.341 \mathrm{a}$ \\
\hline Época $1^{\circ}$ e $2^{\circ}$ nó & $2.304 \mathrm{a}$ & $2.372 \mathrm{~b}$ & $2.644 \mathrm{a}$ & $3.813 \mathrm{a}$ & $2.598 \mathrm{a}$ & $3.692 \mathrm{a}$ & $3.585 \mathrm{a}$ & $3.268 \mathrm{a}$ \\
\hline Época $2^{\circ}$ e $3^{\circ}$ nó & $2.344 \mathrm{a}$ & $2.515 \mathrm{a}$ & $2.585 \mathrm{a}$ & $3.856 \mathrm{a}$ & $2.630 \mathrm{a}$ & $3.624 \mathrm{a}$ & $3.768 \mathrm{a}$ & $3.279 \mathrm{a}$ \\
\hline $\mathrm{CV}(\%)$ & 14,0 & 9,0 & 8,3 & 6,8 & 15,0 & 8,8 & 11,7 & 6,9 \\
\hline
\end{tabular}

\/ Dose em $\mathrm{kg} \mathrm{ha}^{-1}$, aplicada na forma de uréia no perfilhamento; médias seguidas da mesma letra nas colunas não diferem significativamente pelo teste da DMS ( $p<5 \%) ; C V=$ coeficiente de variação.

O diâmetro do caule não foi afetado de forma substancial pela dose de nitrogênio e pela época de aplicação de trinexapac-ethyl (Tabela 1). Os cultivares Ônix e Supera mostraram interação entre doses e épocas de aplicação de trinexapac-ethyl, distintamente de OR-1, CD-104, CD-105, Vanguarda e CEP-24. Os cultivares responderam de forma característica, tendo alguns demonstrado resposta quadrática e outros, linear. Alcover e CD-104 não mostraram resposta à dose nem a época de aplicação (Tabela 2). A resposta pouco acentuada do diâmetro do caule ao trinexapac-ethyl também foi observada em outro trabalho (Zagonel et al., 2002a), mesmo com variações na altura das plantas. 
O indice de colheita aparente diminuiu com o aumento da dose de nitrogênio somente nos cultivares CD-104, Vanguarda e CEP-24 (Tabela 1). Na época de aplicação do regulador os cultivares mostraram-se indiferentes, exceto CD-105 (Tabela 1). Para as doses do trinexapac-ethyl, os cultivares responderam de maneira diferenciada (Tabela 2).

Com o aumento da dose do nitrogênio ocorreu aumento do número de grãos $\mathrm{m}^{-2}$ para os cultivares CD-104, Ônix, Supera e CEP-24 e aumento do peso de mil grãos para os cultivares Ônix e CEP-24 (Tabela 1). Em relação à época de aplicação do trin exapac-ethyl, os cultivares responderam de forma distinta, com maior ou menor peso e número de grãos em função do estádio de aplicação (Tabela 1). A resposta dos cultivares ao aumento da dose de trinexapac-ethyl variou tanto para o número como para o peso de grãos, sendo a função quadrática a de maior ocorrência para o número de grãos e a linear para o peso destes (Tabela 2).

A resposta da produtividade ao nitrogênio depende de fatores como clima, solo e cultivar (Freitas et al., 1994). Os cultivares CD-105 e CEP-24 foram os únicos que responderam ao aumento da dose do nitrogênio, com maior produtividade (Tabela 1). Isso provavelmente ocorreu porque mesmo a menor dose de nitrogênio foi composta da aplicação de $24 \mathrm{~kg} \mathrm{ha}^{-1}$ na base e $50 \mathrm{~kg} \mathrm{ha}^{-1}$ em cobertura, o que, aliado ao alto teor de matéria orgânica do solo, veio suprir as necessidades dos cultivares que não responderam ao aumento da dose do elemento.

O cultivar CD-104 foi o único que respondeu à época de aplicação do trinexapac-ethyl, com maior produtividade para aplicação tardia, entre o 2ㅇ o 3 ํ nó perceptível (Tabela 1).

Tabela 2 - Equação de ajuste de características agronômicas, componentes da produção e produtividade de oito cultivares de trigo em função de doses e épocas de aplicação de trinexapac-ethyl. Ponta Grossa-PR, 2005

\begin{tabular}{|c|c|c|}
\hline Cultivar & Diâme tro do caule (mm) & Índice de colheita aparente \\
\hline OR-1 & $Y=2,87-0,00014 x$ & $Y=0,36+0,00056 x-0,0000009 x^{2}$ \\
\hline CD-104 & NS & $Y=0,39+0,00061 x-0,00000086 x^{2}$ \\
\hline CD-105 & $Y=3,05-0,00029 x$ & NS \\
\hline Alcover & NS & $Y=0,48+0,00018 x$ \\
\hline Ônix & $\begin{array}{l}\mathrm{E} 1=\mathrm{NS} \\
\mathrm{E} 2=2,92+0,00049 x\end{array}$ & $\begin{array}{l}\mathrm{E} 1=0,30+0,00040 \mathrm{x}-0,0000008 \mathrm{x}^{2} \\
\mathrm{E} 2=\mathrm{NS}\end{array}$ \\
\hline Vanguarda & $Y=2,72+0,00067 x-0,0000090 x^{2}$ & $\begin{array}{l}\mathrm{E} 1=0,29+0,00038 x-0,00000053 x^{2} \\
E 2=0,32+0,00020 x-0,0000003 x^{2}\end{array}$ \\
\hline Supera & $\begin{array}{l}\mathrm{E} 1=3,04-0,00021 x \\
\mathrm{E} 2=\mathrm{NS}\end{array}$ & NS \\
\hline CEP-24 & $Y=3,05+0,00052 x-0,00000063 x^{2}$ & NS \\
\hline Cultivar & $\mathrm{N}^{\mathrm{o}}$ grãos $\mathrm{m}^{-2}$ & Peso de mil grãos (g) \\
\hline OR-1 & $\begin{array}{l}\mathrm{E} 1=\mathrm{NS} \\
\mathrm{E} 2=10524,95-12,15 \mathrm{x}+0,017 \mathrm{x}^{2}\end{array}$ & $\begin{array}{l}\mathrm{E} 1=29,04-0,0081 \mathrm{x} \\
\mathrm{E} 2=27,11+0,012 x-0,000021 x^{2}\end{array}$ \\
\hline CD-104 & $Y=6445,94-1,76 x$ & $Y=27,92-0,0056 x$ \\
\hline CD-105 & NS & NS \\
\hline Alcover & $\begin{array}{l}\mathrm{E} 1=\mathrm{NS} \\
\mathrm{E} 2=7.929,88+4,39-0,016 \mathrm{x}^{2}\end{array}$ & $\mathrm{Y}=26,82+0,017 \mathrm{x}-0,000025 \mathrm{x}^{2}$ \\
\hline Ônix & $\begin{array}{l}\mathrm{E} 1=9.697,32-2,53 x \\
\mathrm{E} 2=10.043,11-5,69 x+0,011 x^{2}\end{array}$ & $\begin{array}{l}E 1=21,78-0,0062 x \\
E 2=24,04-0,0054 x\end{array}$ \\
\hline Vanguarda & $\mathrm{Y}=8.881,24+10,28 \mathrm{x}-0,019 \mathrm{x}^{2}$ & $Y=26,60+0,0033 x-0,000014 x^{2}$ \\
\hline Supera & $\mathrm{Y}=8186,82+1,49 \mathrm{x}$ & NS \\
\hline CEP-24 & $\begin{array}{l}\mathrm{E} 1=5272,56+19,37 \mathrm{x}-0,029 \mathrm{x}^{2} \\
\mathrm{E} 2=\mathrm{NS}\end{array}$ & $\begin{array}{l}\mathrm{E} 1=\mathrm{NS} \\
\mathrm{E} 2=24,84+0,013 \mathrm{x}\end{array}$ \\
\hline
\end{tabular}

E1 = aplicação entre o $1^{\complement}$ e o $2^{\mathrm{a}}$ nó perceptível; E2 = aplicação entre o $2^{\mathrm{a}} \mathrm{e}$ o $3^{\mathrm{a}}$ nó perceptível. 
OR-1

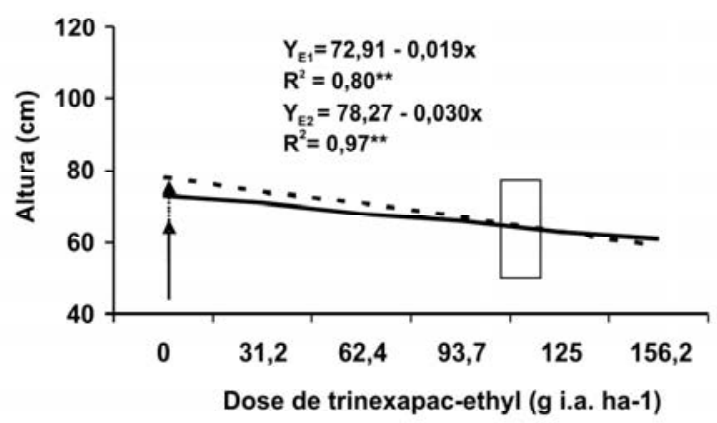

CD-105

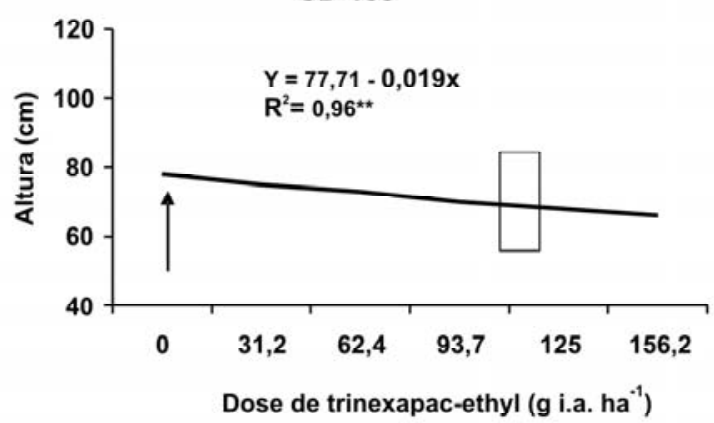

Ônix
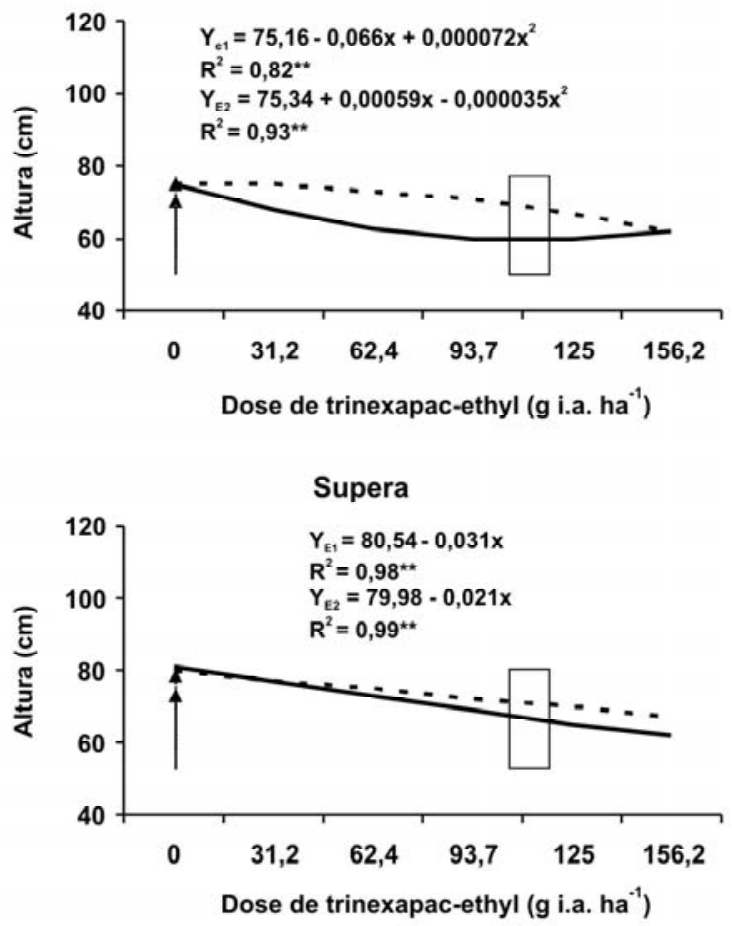

CD-104

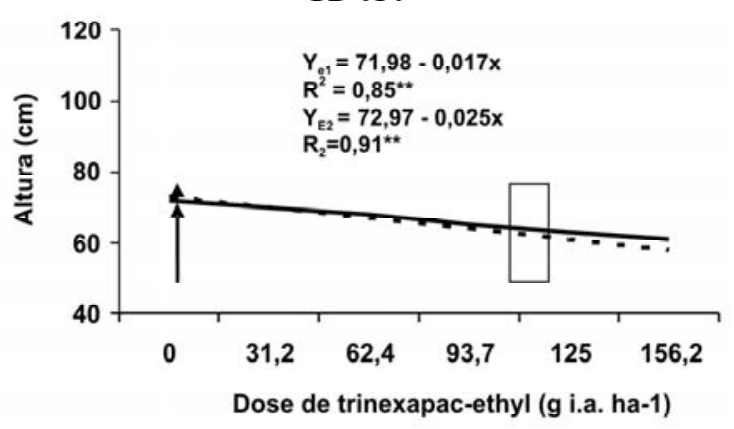

Alcover

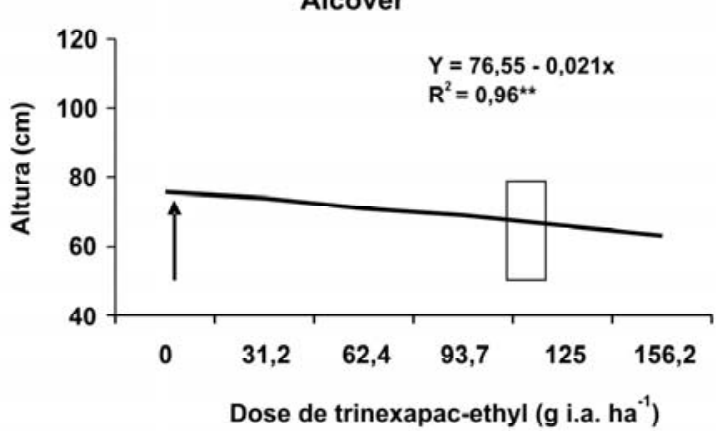

Vanguarda

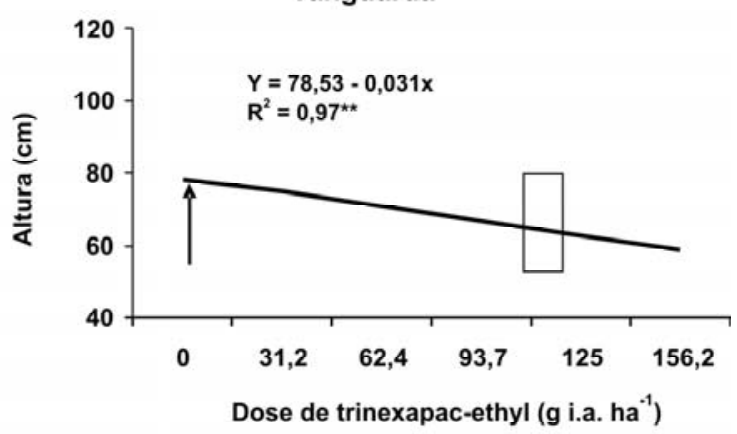

CEP-24

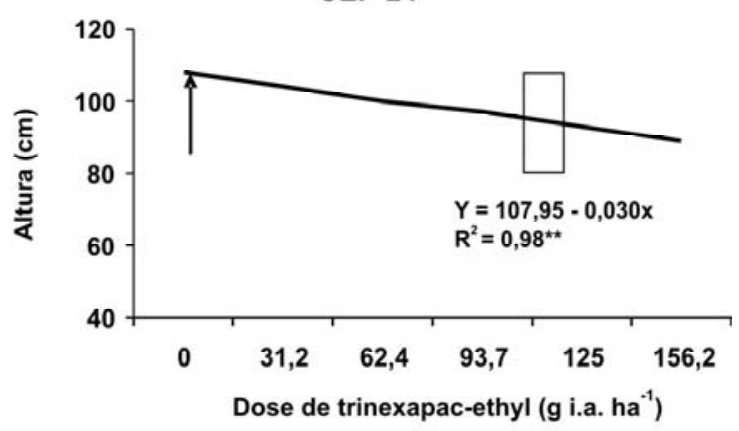

$\mathrm{E}_{1}$ ou média —— $; \mathrm{E}_{2}-----------;$ Dose recomendada $v$; Ponto de máxima $\uparrow$.

Figura 1 - Curvas ajustadas da altura de oito cultivares de trigo em função de doses e épocas de aplicação de trinexapac-ethyl. Ponta Grossa-PR, 2005. 
Com relação às doses do trinexapac-ethyl, exceto para a época tardia de aplicação no cultivar CEP-24 (de resposta linear), os demais, nas duas épocas de aplicação do redutor, responderam de forma quadrática ao aumento da dose, com limite máximo (dose ótima) variável de acordo com o cultivar (Figura 2). A resposta quadrática da produtividade em relação ao aumento da dose do trinexapacethyl e suas interações com a época de aplicação estão ligadas diretamente às alterações causadas pelo redutor na altura das plantas, pelo encurtamento dos entrenós, especialmente o último (pedúnculo). Em trigo, a espiga fica envolta na bainha da folha-bandeira e, com o crescimento do pedúnculo, esta acaba emergindo da bainha. Quanto mais tardia a aplicação do trinexapac-ethyl, maior é a redução do comprimento do pedúnculo, já que o redutor atua de 14 a 21 dias na planta (Fagerness \& Penner, 1998). Se o encurtamento do pedúnculo for acentuado, a espiga, ou parte desta, fica retida na bainha da folhabandeira, interferindo na antese e na formação dos grãos, com efeitos diretos na produtividade. Assim, a redução do rendimento de grãos a partir de determinada dose, observada nos cultivares com resposta quadrática, devese à retenção da espiga. De modo geral, a retenção ocorre em doses baixas para cultivares de menor porte e é uma característica que também foi observada em outro trabalho (Zagonel \& Kunz, 2005).

A maior produtividade (ponto de máxima) para os cultivares foi (doses em $\mathrm{g} \mathrm{ha}^{-1} \mathrm{de}$ trinexapac-ethyl): 65,0 (OR-1), 110,0 (CD-104 época 1), 81,3 (CD-104 época 2), 87,5 (CD105 época 1), 82,5 (CD-105 época 2), 87,5 (Alcover), 78,8 (Ônix), 82,5 (Vanguarda época 1), 63,8 (Vanguarda época 2), 76,3 (Supera) e 132,5 (CEP-24 época 1) (Figura 1). Nota-se que essas doses, com exceção do cultivar de maior altura (CEP-24), estão abaixo da recomendada (de 100 a $125 \mathrm{~g} \mathrm{ha}^{-1}$ ), especialmente quando aplicadas mais tarde, como é visualizado na Figura 2. Como a retenção é maior nas aplicações mais tardias, é necessário reduzir a dose do redutor para se atingir o rendimento máximo nessa época - efeito observado em alguns cultivares (Figura 2). No entanto, a aplicação tardia (época 2) está fora da recomendação de uso do produto (entre o $1^{\circ}$ e o $2^{\circ}$ nó perceptivel) e seu uso deve ser criterioso, não podendo ocorrer atraso na época de aplicação; deve-se destacar que fatores climáticos adversos, que venham a afetar o crescimento das plantas, podem agravar o problema de retenção da espiga.

Esses resultados mostram que tanto a dose como a época de aplicação do trinexapac-ethyl podem e devem ser adequados a cada cultivar, especialmente nos de maior resistência ao acamamento. O uso do redutor nesses cultivares é justificado pelo aumento de produtividade que ele promove e não por redução da estatura e do acamamento (Tabela 1 e Figura 2). Esse efeito foi comprovado também em outros trabalhos (Zagonel et al., 2002a, b, 2005; Rodrigues et al., 2003; ). O aumento de produtividade se deve às mudanças morfológicas causadas pelo produto, que, ao diminuir a altura das plantas, as deixam com uma arquitetura mais adequada para aproveitar os recursos do meio, especialmente a radiação solar, e produzir mais, sendo a arquitetura diferente em relação ao cultivar e à dose do trinexapac-ethyl. Assim, plantas menores redirecionam os fotoassimilados, produzindo maior massa de grãos em relação à massa total da planta, o que é expresso pelo índice de colheita aparente (IC). $\mathrm{Na}$ Tabela 2 observa-se que o IC de cinco cultivares mostrou resposta quadrática ao aumento da dose do trinexapac-ethyl, tal qual a produtividade, o que comprova a vantagem da redução de altura das plantas causada pelo produto em modificar as plantas a ponto de produzir mais.

Com os resultados, conclui-se que o aumento da dose de nitrogênio afetou características da planta e a produtividade de alguns cultivares; a época de aplicação do trinexapacethyl não afetou de forma substancial a produtividade, e sim a altura das plantas, que foi menor, em geral, quanto mais tardia foi a aplicação; e o trinexapac-ethyl reduziu a altura das plantas de todos os cultivares, com intensidade variável com o porte destes. Todos os cultivares apresentaram respostas quadráticas da produtividade em relação às doses de trinexapac-ethyl, ocorrendo aumento da produção com o aumento da dose do redutor, até um limite máximo variável com o cultivar. No entanto, em sete dos oito cultivares estudados, esse limite foi obtido com doses inferiores às recomendadas comercialmente. 
OR-1
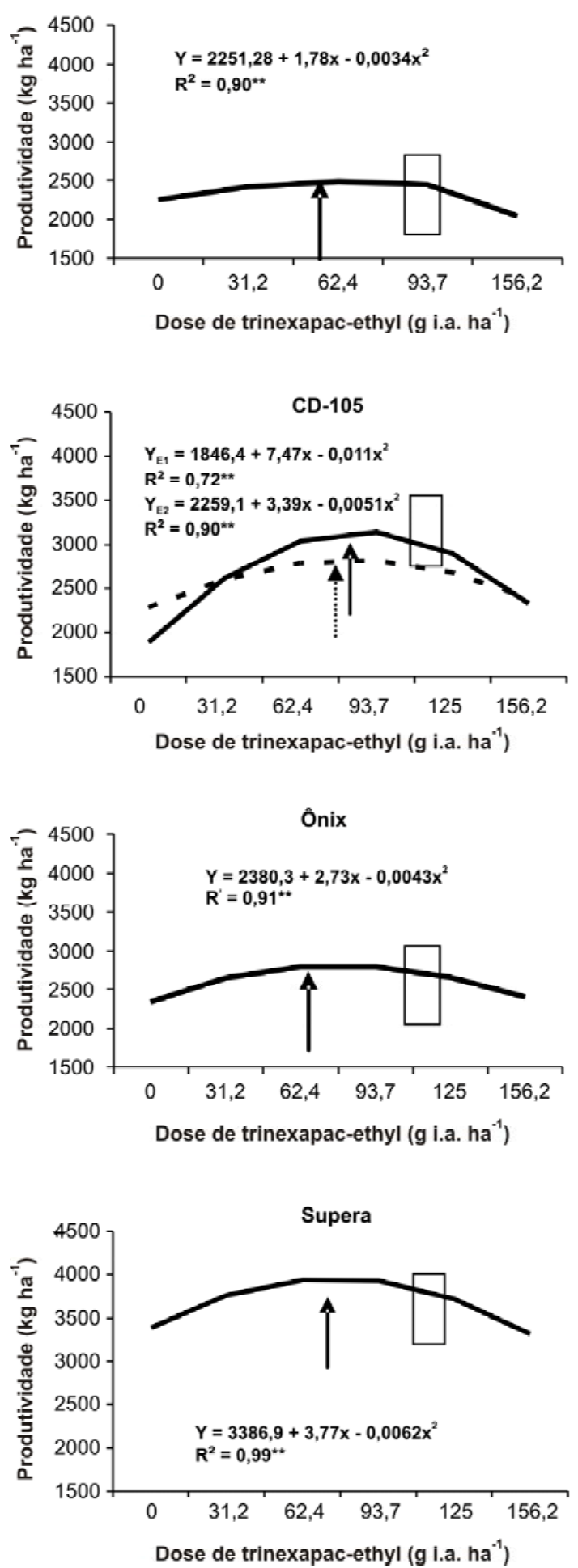

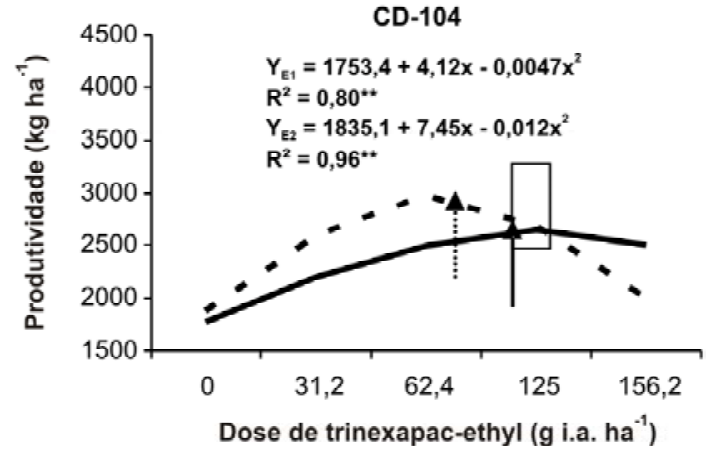

Alcover
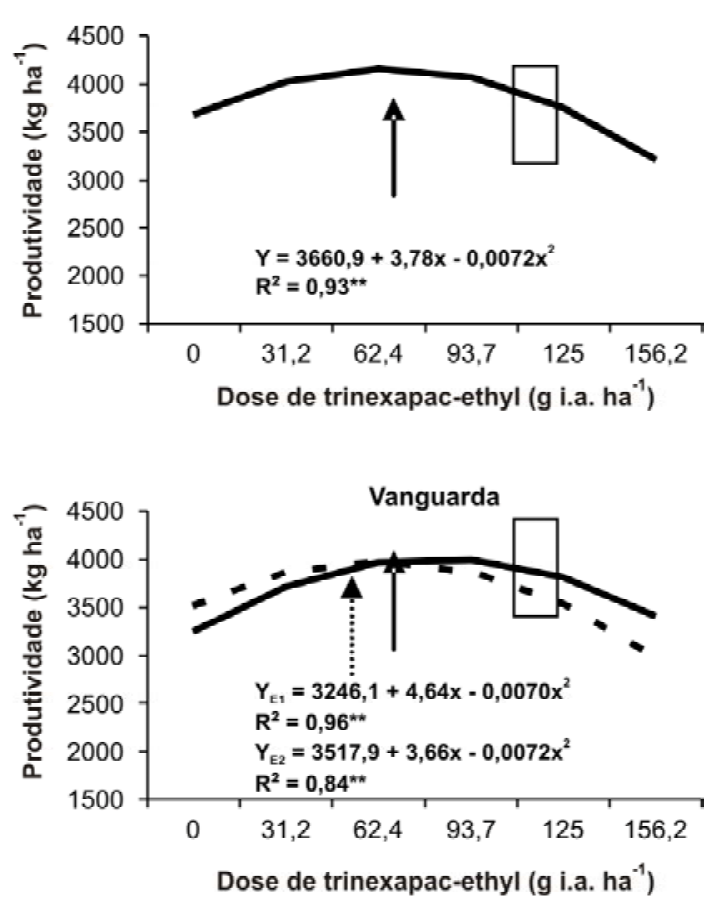

CEP-24

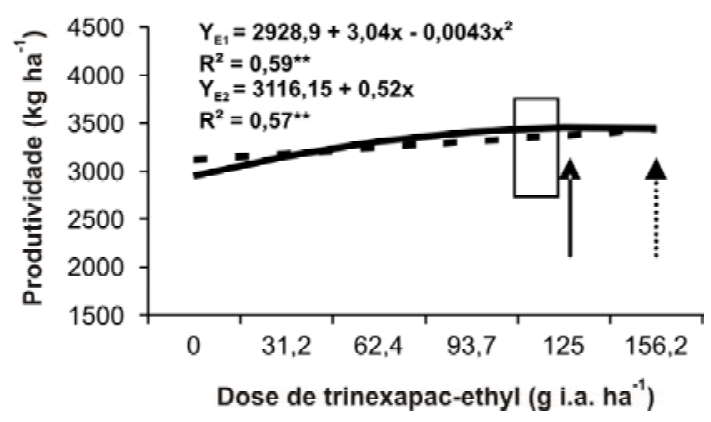

$\mathrm{E}_{1}$ ou média —— $; \mathrm{E}_{2}----------;$ Dose recomendada $v$; Ponto de máxima $\uparrow$.

Figura 2 - Curvas ajustadas da produtividade de oito cultivares de trigo em função de doses e épocas de aplicação de trin exapac-ethyl. Ponta Grossa-PR. 2005. 


\section{LITERATURA CITADA}

AMREIN, J.; RUFENER, M.; QUADRANTI, M. The use of CGA 163'935 as a growth regulator in cereals and oilseed rape. In: BRIGHTON CROP PROTECTION CONFERENCE - WEEDS, 1989, Switzerland. Proceedings... Switzerland: Ciba Geigy, 1989. p. 2-12.

DAVIES, P. J. The plant hormones: their nature, occourrence, and functions. In: DAVIES, P. J. Plant hormones and their role in plant growth and development. Netherlands: Kluwer Academic, 1987. p. 1-23.

FAGERNESS, M. J.; PENNER, D. Spray application parameters that influence the growth inhibiting effects of trinexapac-ethyl. Crop Sci., v. 38, p. 1028-1035, 1998.

FREITAS, J. G. et al. Produtividade e resposta de genótipos de trigo ao nitrogênio. Bragantia, v. 53, n. 2, p. 281-90, 1994.

HECKMAN, N. L. et al. Influence of trinexapac-ethyl on respiration of isolated wheat mitochondria. Crop Sci., v. 42, p. 423-427, 2002.

INSTITUTO AGRONÔMICO DO PARANÁ - IAPAR. Informações técnicas para a cultura de trigo no Paraná 2000. Londrina: 2000. 152 p. (IAPAR, Circular, 109).

MUNDSTOCK, C. M. Cultivo dos cereais de estação fria: trigo, cevada, aveia, centeio, alpiste, triticale. Porto Alegre: NBS, 1983. $265 \mathrm{p}$.

NAKAYAMA, K. et al. Effects of a plant-growth regulator, prohexadione, on the biosynthesis of gibberellins in cell-free systems derived from immature seeds. Plant Cell Physiol., v. 31, p. 1183-1190, 1990.

RODRIGUES, O. et al. Redutores de crescimento. Passo Fundo: Embrapa Trigo, 2003. (Embrapa Trigo, Circular Técnica, 14).
SILVA, D. B.; GOTO, W. S. Resposta do trigo de sequeiro ao nitrogênio, após soja precoce, na região do Alto Paranaíba, MG. Pesq. Agropec. Bras., v. 26, n. 9, p. 1401-1405, 1990.

VIEIRA, R. D. et al. Efeito de doses e épocas de aplicação de nitrogênio em cobertura na produção e na qualidade fisiológica de sementes de trigo. Científica, v. 23, n. 2, p. 257-264, 1995.

WEILER, E. W.; ADAMS, R. Studies on the action of the new growth retardant CGA 163'935. In: BRIGHTON CROP PROTECTION CONFERENCE - WEEDS, 1991,

Switzerland. Proceedings... Switzerland: Ciba Geigy, 1991. p. $1133-1138$.

ZAGONEL, J. et al. Doses de nitrogênio e densidades de plantas com e sem um regulador de crescimento afetando o trigo, cultivar OR-1. Ci. Rural, v. 32, p. 25-29, 2002a.

ZAGONEL, J.; VENANCIO, W. S.; KUNZ, R. P. Efeito de regulador de crescimento na cultura do trigo submetido a diferentes doses de nitrogênio e densidade de plantas. Planta Daninha, v. 20, p. 471-476, 2002 b.

ZAGONEL, J. Efeitos do regulador de crescimento trinexapac-ethyl no desenvolvimento e na produtividade do trigo. In: REUNIÃO DA COMISSÃO CENTRO SUL BRASILEIRA DE PESQUISA DE TRIGO, 18., 2003, Guarapuava. Palestras.... Guarapuava: FAPA, 2003. v. 1. p. 199-202.

ZAGONEL, J.; FERNANDES, E. C.; KORELLO, S. Efeitos de regulador de crescimento (trinexapac-ethyl) da irrigação e da dose de nitrogênio na cultura do trigo. In: REUNIÃO DA COMISSÃO CENTRO SUL BRASILEIRA DE PESQUISA DE TRIGO, 20., 2005, Londrina. Resumos.... Londrina: Embrapa Soja, 2005. p. 130-134.

ZAGONEL, J.; KUNZ, R. P. Doses de nitrogênio e de regulador de crescimento (Moddus) afetando o trigo. In: REUNIÃO DA COMISSÃO CENTRO SUL BRASILEIRA DE PESQUISA DE TRIGO, 20., 2005, Londrina. Resumos.... Londrina: Embrapa Soja, 2005. p. 135-140. 